\title{
The Utilization of Complementary and Alternative Medicine among Saudi Older Adults: A Population-Based Study
}

\author{
Mohammad H. Aljawadi (D), ${ }^{1}$ Abdullah T. Khoja, ${ }^{2}$ Azzam D. AlOtaibi, ${ }^{3}$ \\ Khalid Turki Alharbi, ${ }^{4}$ Muhannad Abdulwahed Alodayni, ${ }^{5}$ Mansour S. AlMetwazi, ${ }^{1}$ \\ Azher Arafah, ${ }^{1}$ Sulaiman A. Al-Shammari, ${ }^{6}$ and Tawfik A. Khoja ${ }^{7}$ \\ ${ }^{1}$ Department of Clinical Pharmacy, College of Pharmacy, King Saud University, Riyadh, Saudi Arabia \\ ${ }^{2}$ Public Health and Family Medicine Departments, College of Medicine, \\ Al-Imam Muhammad Ibn Saud Islamic University (IMSIU), Riyadh, Saudi Arabia \\ ${ }^{3}$ Department of Medicine, College of Medicine, Al-Imam Muhammad Ibn Saud Islamic University (IMSIU), Riyadh, \\ Saudi Arabia \\ ${ }^{4}$ Pharmacy Services, Prince Sultan Military Medical City, Riyadh, Saudi Arabia \\ ${ }^{5}$ College of Medicine, Imam Muhammad Ibn Saud Islamic University, Riyadh, Saudi Arabia \\ ${ }^{6}$ Department of Family and Community Medicine, College of Medicine, King Saud University, Riyadh, Saudi Arabia \\ ${ }^{7}$ Health Ministers' Council for the Cooperation Council States, Riyadh, Saudi Arabia
}

Correspondence should be addressed to Mohammad H. Aljawadi; maljawadi@ksu.edu.sa

Received 7 February 2020; Revised 3 June 2020; Accepted 22 June 2020; Published 7 August 2020

Academic Editor: Wenyi Kang

Copyright (c) 2020 Mohammad H. Aljawadi et al. This is an open access article distributed under the Creative Commons Attribution License, which permits unrestricted use, distribution, and reproduction in any medium, provided the original work is properly cited.

\begin{abstract}
Background. Complementary and alternative medicine (CAM) is an integral part of patients' therapeutic experience worldwide. Among Saudi older adults, less is known about CAM utilization. Objectives. To determine the prevalence, patterns, and factors associated with CAM utilization among SOA. Methods. In the Saudi National Survey for Elderly Health (SNSEH), subjects were asked about CAM use during the last twelve months before the interview. CAM use was defined as any use of herbal products, acupuncture, bloodletting, cauterization, medical massage, bones manual manipulation, honey, or religious rituals. Demographic characteristics included gender, age, marital status, region, educational level, and residence area. In addition, multiple comorbidities were included as possible factors that may be associated with CAM use. Multivariable logistic regression was used to explore factors associated with CAM utilization. All statistical analyses were done using STATA v.14. Results. Out of 2946 respondents, $50.4 \%$ were males, the mean age was $70.3 \pm 8.3$ years, and $70 \%$ were illiterate. CAM use was prevalent $(62.5 \%)$. The most common CAM types were herbal products (25.4\%), acupuncture (21.2\%), bloodletting (12\%), honey (9.5\%), cauterization (7.4\%), medical massage and bones manual manipulation (4\%), and traditional bone setting (2.1\%). In the multivariable regression, age, gender, and marital status did not have an impact on the odds of using CAM. Subjects from rural areas were 2.92 times more likely to use CAM compared with subjects in urban areas $(\mathrm{OR}=2.92$; 95\%CI: 2.28-3.75). Subjects with metabolic disorders $(\mathrm{OR}=0.50 ; 95 \% \mathrm{CI}: 0.42-0.60)$ or kidney disease were less likely to use CAM (OR = 0.30; 95\%CI: 0.14-0.64). About pain, CAM is used more in neck pain $(\mathrm{OR}=1.69 ; 95 \% \mathrm{CI}: 1.30-2.21)$ and also used in back pain $(\mathrm{OR}=1.22 ; 95 \% \mathrm{CI}: 1.03-1.46)$. Conclusions. CAM use was very prevalent among SOA. Clinicians and pharmacists must ask about CAM use among older adults as many of CAM may interact with patients medications.
\end{abstract}

\section{Introduction}

Complementary and alternative medicine (CAM) is a diverse group of interventions, practices, and products that are not considered as part of the usual care $[1,2]$.
They include different categories, such as herbal products, acupuncture, bloodletting, cauterization, medical massage, and manual manipulation of bones, as well as religious rituals and practices. The institute of medicine has listed more than one hundred interventions/practices 
under CAM [3]. While few interventions and practices, such as chiropractic, bloodletting, and massage therapy, have been regulated, many are being practiced without any form of regulations.

Despite the lack of regulations, the utilization of CAM is widespread worldwide. In Saudi Arabia, the prevalence of CAM use among adults ranged between $65 \%$ and $80 \%[4,5]$. This noticeable popularity of CAM has also been documented in other countries. For instance, Eisenberg et al. found that 34\% of the US population have used CAM during a year [1]. Another study in the USA suggested that the prevalence of CAM utilization among adults can be as high as 62\% [6]. Furthermore, $49 \%$ of the population in France, $46 \%$ in Germany, and $69 \%$ in Australia had used CAM treatment at some point in their lives $[7,8]$.

Certain factors have been associated with CAM use among older adults, including the availability of health caregivers in the area of residence, gender, education level, and ethnicity [9-11]. In addition, certain disease conditions such as insomnia, back pain, colds, and Alzheimer's disease were associated with the use of CAM among older adults $[9,11]$.

There are multiple reasons for CAM utilization, such as the assumption of CAM safety compared to conventional medicines, the perceived possible beneficial effects, having multiple medical conditions, and decreased functional activity [12-15]. Since many older adults have multiple medical conditions and decreased functional activities, one may expect high CAM utilization among this segment of the population. Many studies have documented patients have been using CAM for many conditions such as diabetes mellitus (DM), musculoskeletal, cardiac, neurological, urogenital diseases, and mood disorders [6, 16-18]. Therefore, with a high prevalence of use and multiple disease conditions, CAM users may be at risk of potentially harmful interactions between their conventional treatments and CAM products $[1,8,14,16,19,20]$.

For various reasons, older adults appear to be more inclined to use CAM compared to younger age groups. This propensity has been examined in various research worldwide. The higher prevalence of multiple medical conditions, decreased functional activity, the assumption of CAM safety compared to conventional medicines, perceived therapeutic effects are among the top reasons why CAM utilization appears to be more prevalent in older adults [12-15].

The Saudi geriatric population was estimated to be $3.2 \%$ of the total Saudi population in 2018 [21]. Therefore, exploring and understanding the extent and pattern of CAM utilization in Saudi Arabia is essential for healthcare providers and decision-makers to evaluate the current healthcare practices and to develop strategies to improve health outcomes and health service planning. Furthermore, there are very few published studies concerning CAM use among older adults in the middle east and none in Saudi Arabia.

Despite the aforementioned reasons, most studies focused on CAM utilization among adults or pediatric populations with no particular focus on CAM use in older adults. In Saudi Arabia, many studies looked at CAM use among samples where Saudi older adults (SOA) were only a subgroup of study samples rather than being the main focus of the study [18, 22-37]. For instance, Al-Faris and colleagues conducted a cross-sectional study that examined CAM use in 1408 Saudi adults in the Riyadh region. They found that $68 \%$ of the subjects had used CAM during the previous year and that the most critical determinant of CAM use was the perceived failure of conventional medical treatments [4]. Another study was conducted in 2010 in Riyadh city, and surrounding governorates found that among 518 participants, $85 \%$ of subjects or one of their family members has used some form of CAM before [5]. However, these studies represent a sample of SOA and cannot be representative of the whole SOA as many of them were not nationally representative samples. Besides, none of those above studies were able to look at the relationship between CAM use and overall mortality despite the fact that few studies have documented increase perception of death with CAM or death due to CAM utilization. In contrast, others have shown survival benefits due to the introduction of CAM in patients' therapeutic plan [38-41]. Therefore, the objectives of this study are to determine the prevalence and factors associated with CAM utilization among SOA. In addition, to determine the effect of CAM utilization on mortality among SOA. The outcomes of this study are essential for healthcare providers and decision-makers to evaluate healthcare practices and to develop strategies that improve health outcomes among SOA.

\section{Methods}

2.1. Data Source. Data was based on the Saudi National Survey for Elderly Health (SNSEH). It is a nationwide, representative, population-based, cross-sectional survey of SOA who are 60 years of age or older. The survey was conducted between 2006 and 2007 and aimed to evaluate the health status and healthcare provided to SOA. The survey is one of the most extensive national health surveys designed to capture healthrelated information among older adults in Saudi Arabia. The survey was described in detail in an earlier study [42].

2.2. Exposure. In this study, CAM use was defined as any use of herbal products, acupuncture, bloodletting, cauterization, medical massage, manual manipulation of bones, honey, or religious rituals during the previous twelve months of the interview. Since religious rituals are very common in the Saudi Arabian society, they were defined as going to a scholar for performing the prayers and not self-prayers. The categories of CAM were based on the cultural practices in Saudi Arabia. The subjects were asked if they have been using any of these categories as a CAM.

\subsection{Potential Factors Associated with CAM Use.} Demographic characteristics included gender, age, marital status, region, educational level, monthly income, and the area of residence. Besides, DM, depression, hypertension, cognitive impairment, obesity, cancer, metabolic disorders, 
acute and chronic kidney disease, and neck and back pain were also included as possible factors that may be associated with CAM use.

2.4. Study Design. This was a cross-sectional study. The sample included Saudi citizens of sixty years of age or older. To have a nationally representative sample, a complex survey approach was used where the point estimate of disease or disability was assumed to be $10 \%, 95 \%$ level of significance, precision degree 0.02 , design effect of 2.5 , and $80 \%$ response rate $80 \%$. Consequently, the suggested sample size was 2704 subjects. A cluster size of 31 subjects was chosen, considering an interclass correlation of 0.05 . Furthermore, through the application of Probability Proportional to Size (PPS) sampling and systematic random sampling, 88 clusters were chosen. The cluster frame was created by using a catchment area of primary healthcare centers. Within the cluster frame, a cluster map was used to select both random streets and random household. Trained interviewers contacted the picked-out individuals for two visits to carry on the interview and the physical examinations. Subjects were asked to sign an informed consent if they agreed to participate. However, proxies, that is, legal guardians, were asked to sign in the informed consent form in case of subjects with cognitive impairments. In addition, "proxies were mainly used when physical or intellectual impairments prevented the subject from directly answering the interviewer. Nevertheless, proxies were not used if the questionnaire assists the mental or physical patient status, such as depression scale and cognitive abilities." Lastly, standardized survey weights based on census data were calculated to account for oversampling, nonresponse, and postsampling stratification.

2.5. Statistical Analyses. The cohort was described through frequencies and percentages for all categorical variables. All percentages were adjusted by standardized survey weight to incorporate nonresponse, oversampling, and postsampling stratification. The Chi-square test was used to test the association between the variables of interest and CAM. Bivariable and multivariable logistic regressions were used to explore factors associated with CAM utilization among SOA. Both C-statistic and Hosmer-Lemeshow tests were used to assess the goodness of fit of the logistic regression model.

2.5.1. Survival Analysis. Subjects were followed up until mid-2015 to determine their vital status and time to death. Cox proportional hazard was used to assess the effect of CAM use on nine-year survival adjusting for age, gender, diabetes, hypertension stroke, obesity, cancer, ischemic heart diseases, cognitive impairment, renal failure, place of residence, smoking status, and depression. Subjects were censored if they did not die at the end of the follow-up period. Both Groennesby and Borgan test and graphical plotting of Nelson-Aalen cumulative hazard against CoxSnell Residuals were used to determine the model's goodness of fit [43-45]. All statistical analyses were done using (STATA 14) [46]. The institutional review board approved the study at Imam Mohammad Bin Saud Islamic University (HAPO-01-R-011).

\section{Results}

The demographic characteristics of the subjects are shown in Table 1. The overall sample included 2,946 individuals from the thirteen administrative regions of Saudi Arabia. Out of 2946 respondents, 1759 (50.4\%) were males, the mean age was $70.3 \pm 8.3$ years, and $70 \%$ were illiterate.

During the twelve months before the interview, the overall prevalence of CAM use was $62.5 \%$. There was no noticeable difference in CAM use between men (63.3\%) and women $(62.5 \%)(P=0.627)$. The most common CAM types were herbal products (25.4\%), acupuncture (21.2\%), bloodletting (12\%), honey (9.5\%), cauterization $(7.4 \%)$, medical massage and manual manipulation of bones $(4 \%)$, and lastly traditional bone setting (2.1\%). These groups were not mutually exclusive as subjects may have used more than one CAM type. Figure 1 shows the most common medical conditions reported among CAM users.

Among users of CAM, the most common medical conditions reported were musculoskeletal disorders (26.5\%), followed by cardiac problems (22.4\%), neurological problems $(14.6 \%)$, and diabetes mellitus (13.6\%), as shown in Figure 1 . On the other hand, the least common reason to seek CAM was respiratory problems (4\%). Furthermore, Figure 2 depicts the common reasons for choosing CAM over conventional medical treatments.

In the multivariable regression, age and gender did not have an impact on the odds of using CAM. Compared to subjects who did not smoke, the odds of CAM use were higher among ex-smokers ( $\mathrm{OR}=1.43$; 95\% CI: $1.09-1.88)$, as well as daily smokers (OR $=1.71 ; 95 \% \mathrm{CI}: 1.14-2.55)$ but not among occasional smokers (OR $=1.20$; 95\% CI: 0.47-3.04). Subjects from rural areas were 2.57 times more likely to use CAM compared to subjects in urban areas $(\mathrm{OR}=2.57 ; 95 \%$ CI: 1.98-3.33).

Regarding regional variations in SA, SOA in the western and eastern regions were found to be frequent CAM users compared to the central area $(\mathrm{OR}=1.68 ; 95 \% \mathrm{CI}: 1.32-2.13$; $\mathrm{OR}=2.18 ; 95 \% \mathrm{CI}: 1.62-2.95$, resp.) (Table 2). While the southern part is the least in CAM using $(\mathrm{OR}=0.59 ; 95 \% \mathrm{CI}$ : 0.46-0.76).

Subjects with metabolic disorders $(\mathrm{OR}=0.51 ; 95 \% \mathrm{CI}$ : $0.42-0.61)$ or kidney disease were less likely to use CAM $(\mathrm{OR}=0.30 ; 95 \% \mathrm{CI}: 0.14-0.64)$. In the case of pain management, CAM is used more in neck pain $(\mathrm{OR}=1.69$; 95\% CI: $1.30-2.21)$ and also used in back pain (OR = 1.26; 95\%: 1.05-1.50). Cognitive impairment was associated with lower odds of CAM utilization among SOA (Table 2). Lastly, the C-statistic for the multivariable regression was $74.7 \%$, and the Hosmer-Lemeshow test was not significant $(P=0.07)$.

With regard to nine-year survival, 2,047 subjects had their vital status available for analysis. There was no statistical difference in mortality between subjects who used CAM (29.79\%) and more prominently those who did not $(29.77 \% ; P=0.992)$. In the multivariable Cox 
TABLE 1: Univariable and bivariable analyses of complementary and alternative medicine utilization among Saudi older adults $(N=2,946)$.

\begin{tabular}{|c|c|c|c|c|c|c|c|}
\hline \multirow[t]{2}{*}{ Subjects characteristics } & \multicolumn{2}{|c|}{$\begin{array}{c}\text { Total } \\
N=2,946\end{array}$} & \multicolumn{2}{|c|}{$\begin{array}{c}\text { No CAM } \\
\text { use } n=1096 \\
(37.5 \%)\end{array}$} & \multicolumn{2}{|c|}{$\begin{array}{c}\text { CAM use } \\
n=1850 \\
(62.5 \%)\end{array}$} & \multirow[t]{2}{*}{$\chi^{2}, P$ value } \\
\hline & $n$ & $(\%)$ & $n$ & $(\%)$ & $n$ & $(\%)$ & \\
\hline Gender & & & & & & & 0.627 \\
\hline Female & 1187 & $(49.6)$ & 443 & $(38.3)$ & 744 & $(61.7)$ & \\
\hline Male & 1759 & $(50.4)$ & 653 & $(36.7)$ & 1106 & $(63.3)$ & \\
\hline Age (years) & & & & & & & 0.918 \\
\hline $60-65$ & 1072 & $(37.7)$ & 421 & $(38.6)$ & 651 & $(61.4)$ & \\
\hline $66-70$ & 697 & $(23.2)$ & 250 & $(36.7)$ & 447 & $(63.3)$ & \\
\hline $71-75$ & 504 & $(16.6)$ & 185 & $(37.1)$ & 319 & $(62.9)$ & \\
\hline $76-80$ & 342 & $(11.3)$ & 118 & $(36.2)$ & 224 & $(63.8)$ & \\
\hline $81-85$ & 181 & $(6.1)$ & 67 & $(36.8)$ & 114 & $(63.2)$ & \\
\hline $86-90$ & 101 & (3.4) & 33 & (33.8) & 68 & $(66.2)$ & \\
\hline$>90$ & 49 & (1.8) & 22 & $(43.6)$ & 27 & $(56.4)$ & \\
\hline Education level & & & & & & & 0.212 \\
\hline Illiterate & 1943 & $(69.6)$ & 718 & $(38)$ & 1225 & $(62)$ & \\
\hline Less than 8 years & 705 & $(21.8)$ & 247 & (34) & 458 & (66) & \\
\hline Intermediate or high & 222 & $(6.5)$ & 102 & $(44.4)$ & 120 & $(55.6)$ & \\
\hline University or higher & 76 & $(2.1)$ & 29 & $(34.5)$ & 47 & $(65.5)$ & \\
\hline Smoking history & & & & & & & 0.006 \\
\hline Never smoke & 2375 & $(82.9)$ & 932 & $(39.3)$ & 1443 & $(60.7)$ & \\
\hline Ex-smoker & 385 & (11.4) & 113 & $(29.5)$ & 272 & $(70.5)$ & \\
\hline Occasional smoker & 22 & $(0.7)$ & 8 & $(30.7)$ & 14 & $(69.3)$ & \\
\hline Daily smoker & 164 & (5) & 43 & (26.2) & 121 & (73.8) & \\
\hline Income (SR) & & & & & & & 0.859 \\
\hline$>10000$ & 181 & $(5.6)$ & 82 & $(41.5)$ & 99 & $(58.5)$ & \\
\hline $9,999-7,500$ & 140 & $(4.2)$ & 52 & $(35.4)$ & 88 & $(64.6)$ & \\
\hline $7,499-5,000$ & 318 & $(9.6)$ & 114 & $(35.5)$ & 204 & $(64.5)$ & \\
\hline $4,999-2,500$ & 752 & $(24.2)$ & 269 & $(36.5)$ & 483 & $(63.5)$ & \\
\hline$<2,500$ & 1555 & (56.5) & 579 & $(38)$ & 976 & $(62)$ & \\
\hline Marital status & & & & & & & 0.193 \\
\hline Monogamy & 1741 & $(57.2)$ & 641 & $(36.8)$ & 1100 & $(63.2)$ & \\
\hline Polygamy & 430 & $(13.2)$ & 174 & $(40.5)$ & 256 & (59.5) & \\
\hline Widowed & 584 & (23.1) & 226 & $(39.8)$ & 358 & $(60.2)$ & \\
\hline Single & 115 & $(3.6)$ & 38 & $(33.2)$ & 77 & $(66.8)$ & \\
\hline Separated & 76 & $(2.9)$ & 17 & $(24.2)$ & 59 & $(75.8)$ & \\
\hline Residence & & & & & & & 0.132 \\
\hline Urban & 2398 & $(80.1)$ & 954 & $(40.3)$ & 1444 & (59.7) & \\
\hline Rural & 548 & (19.9) & 142 & $(26.3)$ & 406 & (73.7) & \\
\hline Regions & & & & & & & 0.390 \\
\hline Central & 753 & $(23.2)$ & 308 & $(41.2)$ & 445 & $(58.8)$ & \\
\hline Western & 874 & (31.1) & 257 & $(28.8)$ & 617 & $(71.2)$ & \\
\hline Eastern & 393 & (13.7) & 111 & (34.8) & 282 & $(65.2)$ & \\
\hline Southern & 731 & $(25.1)$ & 314 & $(42)$ & 417 & $(58)$ & \\
\hline Northern & 195 & $(6.9)$ & 106 & $(53.2)$ & 89 & $(46.8)$ & \\
\hline BMI WHO categories & & & & & & & 0.990 \\
\hline Less than 18.5 & 50 & $(1.8)$ & 18 & $(36.2)$ & 32 & $(63.8)$ & \\
\hline From 18.5 to 25 & 872 & $(28.6)$ & 319 & $(37.3)$ & 553 & $(62.7)$ & \\
\hline From 25 to 30 & 1132 & $(37.5)$ & 431 & (37.9) & 701 & $(62.1)$ & \\
\hline More than 30 & 892 & $(32.1)$ & 328 & $(37.2)$ & 564 & $(62.8)$ & \\
\hline Cognitive impairment ${ }^{\mathrm{N}}$ & & & & & & & 0.022 \\
\hline Normal cognition & 2474 & $(82)$ & 872 & $(35.2)$ & 1602 & $(64.8)$ & \\
\hline Mild & 312 & (11.9) & 144 & $(47.7)$ & 168 & $(52.3)$ & \\
\hline Moderate & 103 & (4) & 49 & $(46.3)$ & 54 & $(53.7)$ & \\
\hline Severe & 57 & $(2.2)$ & 31 & $(52.5)$ & 26 & (47.5) & \\
\hline Depression $\diamond$ & & & & & & & 0.146 \\
\hline Normal $(<5)$ & 2192 & $(73.3)$ & 853 & $(39.2)$ & 1339 & $(60.8)$ & \\
\hline Suggestive (5-10) & 682 & $(24.2)$ & 218 & (32.4) & 464 & $(67.6)$ & \\
\hline Depression $(>10)$ & 72 & $(2.6)$ & 25 & $(37.5)$ & 47 & $(62.5)$ & \\
\hline Diabetes mellitus & & & & & & & 0.905 \\
\hline No & 1625 & $(55.6)$ & 597 & $(37.3)$ & 1028 & $(62.7)$ & \\
\hline
\end{tabular}


TABle 1: Continued.

\begin{tabular}{|c|c|c|c|c|c|c|c|}
\hline Yes & 1321 & $(44.4)$ & 499 & $(37.7)$ & 822 & $(62.3)$ & \\
\hline Hypertension & & & & & & & 0.519 \\
\hline No & 1072 & $(35.5)$ & 416 & $(38.6)$ & 656 & $(61.4)$ & \\
\hline Yes & 1874 & $(64.5)$ & 680 & (36.9) & 1194 & $(63.1)$ & \\
\hline Stroke & & & & & & & 0.226 \\
\hline No & 2906 & $(98.7)$ & 1077 & $(37.3)$ & 1829 & $(62.7)$ & \\
\hline Yes & 40 & $(1.3)$ & 19 & $(48.9)$ & 21 & $(51.1)$ & \\
\hline Cancer & & & & & & & 0.048 \\
\hline No & 2892 & $(98.1)$ & 1067 & $(37.2)$ & 1825 & $(62.8)$ & \\
\hline Yes & 54 & $(1.9)$ & 29 & $(54.3)$ & 25 & $(45.7)$ & \\
\hline Ischemic heart disease & & & & & & & 0.589 \\
\hline No & 2838 & $(96.5)$ & 1053 & $(37.4)$ & 1785 & $(62.6)$ & \\
\hline Yes & 108 & $(3.5)$ & 43 & $(40.6)$ & 65 & $(59.4)$ & \\
\hline Metabolic disorders & & & & & & & $<0.001$ \\
\hline No & 2106 & $(71.3)$ & 685 & $(32.1)$ & 1421 & $(67.9)$ & \\
\hline Yes & 840 & $(28.7)$ & 411 & $(50.8)$ & 429 & $(49.2)$ & \\
\hline Acute kidney failure and chronic kidney disease & & & & & & & 0.012 \\
\hline No & 2912 & $(98.9)$ & 1076 & $(37.2)$ & 1836 & $(62.8)$ & \\
\hline Yes & 34 & $(1.1)$ & 20 & $(61)$ & 14 & $(39)$ & \\
\hline Neck pain & & & & & & & 0.016 \\
\hline No & 2539 & $(85.4)$ & 990 & $(39.2)$ & 1549 & $(60.8)$ & \\
\hline Yes & 407 & $(14.6)$ & 106 & $(27.6)$ & 301 & $(72.4)$ & \\
\hline Back pain & & & & & & & 0.024 \\
\hline No & 1694 & $(56.3)$ & 685 & $(41)$ & 1009 & (59) & \\
\hline Yes & 1252 & $(43.7)$ & 411 & (33) & 841 & (67) & \\
\hline Blood in stools & & & & & & & 0.091 \\
\hline No & 2882 & (97.9) & 1065 & $(37.2)$ & 1817 & $(62.8)$ & \\
\hline Yes & 64 & $(2.1)$ & 31 & $(49.8)$ & 33 & $(50.2)$ & \\
\hline Headache & & & & & & & 0.315 \\
\hline No & 1153 & $(37.4)$ & 469 & (39.9) & 684 & $(60.1)$ & \\
\hline Yes & 1793 & $(62.6)$ & 627 & $(36)$ & 1166 & $(64)$ & \\
\hline Fainting & & & & & & & $<0.001$ \\
\hline No & 2490 & $(84.1)$ & 1010 & $(40.9)$ & 1480 & $(59.1)$ & \\
\hline Yes & 456 & (15.9) & 86 & (19.6) & 370 & $(80.4)$ & \\
\hline Feeling fatigued & & & & & & & 0.022 \\
\hline No & 363 & $(13.2)$ & 177 & $(49.3)$ & 186 & $(50.7)$ & \\
\hline Yes & 2583 & $(86.8)$ & 919 & $(35.7)$ & 1664 & $(64.3)$ & \\
\hline Availability and accessibility of a pharmacy within your locality or village? & & & & & & & 0.061 \\
\hline Not available nor accessible & 222 & $(8)$ & 91 & $(40.3)$ & 131 & $(59.7)$ & \\
\hline Available only & 568 & (20) & 166 & $(29.4)$ & 402 & $(70.6)$ & \\
\hline Accessible only & 179 & $(6.4)$ & 38 & $(22.5)$ & 141 & $(77.5)$ & \\
\hline Available and accessible & 1977 & $(65.7)$ & 801 & $(41)$ & 1176 & (59) & \\
\hline Availability and accessibility of a health center within your locality or village? & & & & & & & 0.549 \\
\hline Not available nor accessible & 95 & $(3.4)$ & 33 & $(35.9)$ & 62 & $(64.1)$ & \\
\hline Available only & 434 & $(15.4)$ & 136 & $(31.6)$ & 298 & $(68.4)$ & \\
\hline Accessible only & 148 & $(5.1)$ & 52 & $(35.6)$ & 96 & $(64.4)$ & \\
\hline Available and accessible & 2269 & $(76.1)$ & 875 & (38.9) & 1394 & $(61.1)$ & \\
\hline Availability and accessibility of a hospital within your locality or village? & & & & & & & 0.689 \\
\hline Not available nor accessible & 203 & $(7.1)$ & 63 & $(27.8)$ & 140 & $(72.2)$ & \\
\hline Available only & 717 & $(25.2)$ & 265 & $(36.5)$ & 452 & $(63.5)$ & \\
\hline Accessible only & 240 & $(8.2)$ & 85 & $(35.9)$ & 155 & $(64.1)$ & \\
\hline Available and accessible & 1786 & $(59.5)$ & 683 & $(39.3)$ & 1103 & $(60.7)$ & \\
\hline
\end{tabular}

SR : Saudi riyals in 2007; BMI : body mass index; WHO : World Health Organization; ${ }^{\aleph}$ based on Short Portable Mental Status Questionnaire (SPMSQ); $\diamond$ based on Geriatric Depression Scale; ${ }^{*} P<0.05,{ }^{* *} P<0.01$, and ${ }^{* * *} P<0.001$.

proportional hazard regression, the hazard ratio of death between 2006 and 2015 was 0.96 , with a 95\%CI (0.81-1.14) indicating no difference in mortality between the two groups (Figure 3 ). The graphical plotting of
Nelson-Aalen cumulative hazard against Cox-Snell Residuals (Figure 4) shows a good fit of the model by the superimposition of the two plots over each other. In addition, the Groennesby and Borgan test that was based 


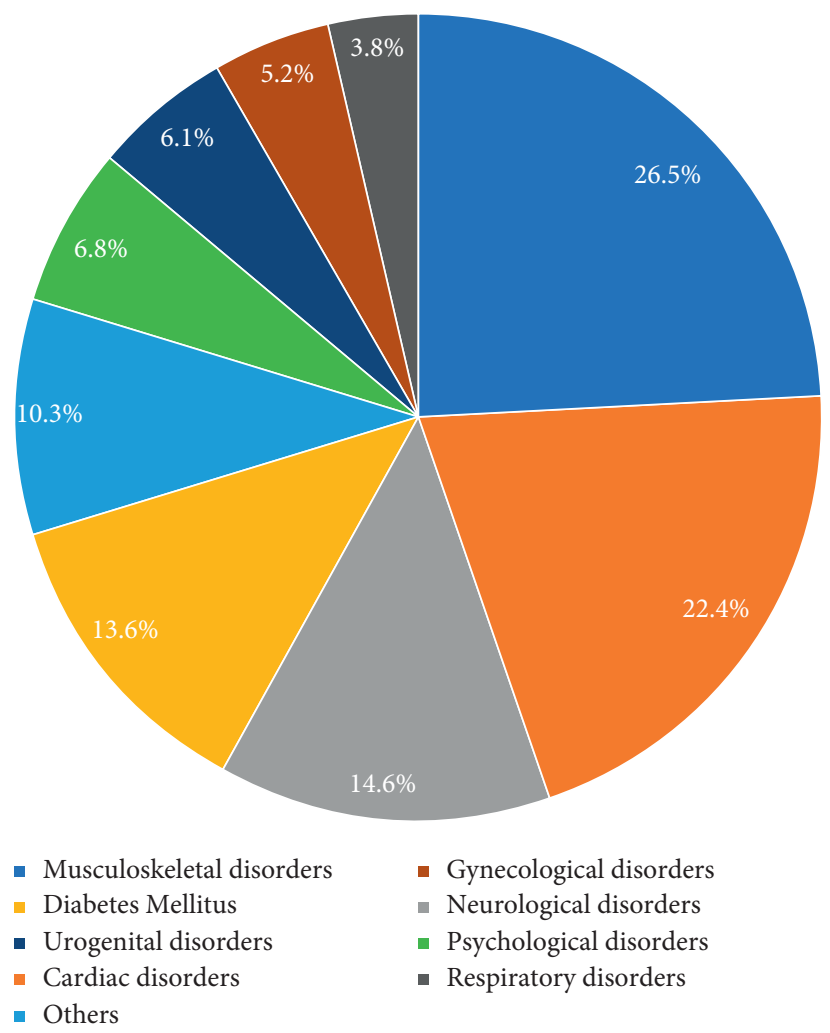

FIGURE 1: The most common disorders for using complementary and alternative medicines among Saudi older adults $(N=2,946)$.

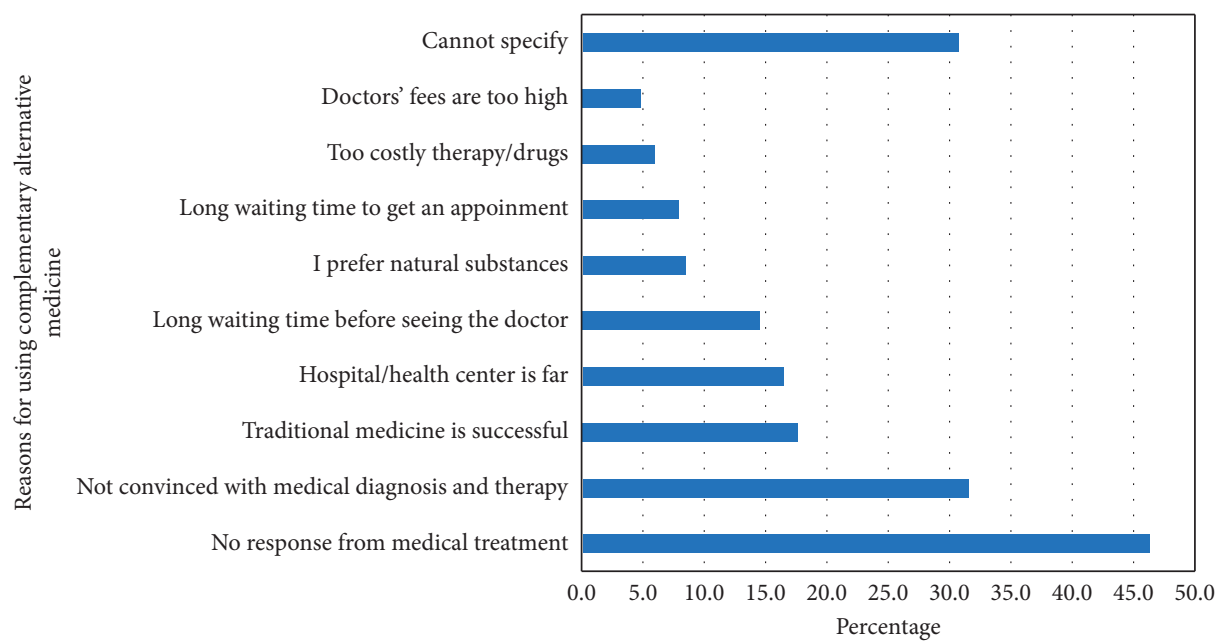

FigURE 2: The most common reasons for using complementary and alternative medicine over conventional treatment among Saudi older adults $(N=2,946)$.

on ten quantiles of risk was insignificant $(P=0.5274)$, indicating a good fit of the model.

\section{Discussion}

In this study, CAM utilization was prevalent among Saudi older adults at $62.5 \%$. The prevalence of CAM use varies between studies and countries. For example, In the USA, Clarke et al. reported that $40 \%$ to $60 \%$ of US citizens had used CAM during the twelve months before the administration of the national health interview surveys [47]. In Europe, CAM utilization over one year was $23 \%$ in Denmark, $49 \%$ in France, and $46 \%$ in Germany [7]. Such differences in the prevalence can be related to demographics [48], locality of herbs, or the difference CAM definition. For instance, bloodletting, as a CAM in Saudi Arabia, constituted around 19\% of all CAM used by SOA. On the other hand, none of those above countries 
TABLE 2: Multivariable logistic regression of factors associated with utilization of complementary alternative medicine among Saudi older adults 2006-2007 $(N=2,946)$.

\begin{tabular}{|c|c|c|}
\hline Characteristics & OR & $95 \% \mathrm{CI}$ \\
\hline Male & 0.919 & {$[0.728,1.158]$} \\
\hline Age (60-65) & 1 & {$[1,1]$} \\
\hline $66-70$ & 1.051 & {$[0.842,1.311]$} \\
\hline $71-75$ & 1.064 & {$[0.828,1.366]$} \\
\hline $76-80$ & 1.18 & {$[0.880,1.583]$} \\
\hline $81-85$ & 0.964 & {$[0.659,1.412]$} \\
\hline $86-90$ & 1.302 & {$[0.786,2.157]$} \\
\hline$>90$ & 0.687 & {$[0.354,1.330]$} \\
\hline Level of education (ref: illiterate) & 1 & {$[1,1]$} \\
\hline Less than 8 years & 1.027 & {$[0.819,1.289]$} \\
\hline Intermediate to high school & $0.606^{* *}$ & {$[0.417,0.881]$} \\
\hline University or higher & 0.921 & {$[0.503,1.689]$} \\
\hline Smoking history (ref: never smoke) & 1 & {$[1,1]$} \\
\hline Ex-smoker & $1.430^{*}$ & {$[1.089,1.877]$} \\
\hline Occasional smoker & 1.195 & {$[0.471,3.037]$} \\
\hline Daily smoker & $1.707^{* *}$ & {$[1.144,2.547]$} \\
\hline Income (SR) (ref: < 2,500) & 1 & {$[1,1]$} \\
\hline$>10000$ & 1.018 & {$[0.677,1.530]$} \\
\hline $9,999-7,500$ & 1.536 & {$[0.998,2.363]$} \\
\hline $7,499-5,000$ & 1.222 & {$[0.903,1.655]$} \\
\hline $4,999-2,500$ & 1.165 & {$[0.945,1.438]$} \\
\hline Marital status (ref: monogamy) & 1 & {$[1,1]$} \\
\hline Polygamy & 0.826 & {$[0.647,1.054]$} \\
\hline Widowed & 0.85 & {$[0.661,1.093]$} \\
\hline Single & 0.915 & {$[0.588,1.424]$} \\
\hline Separated & $2.399^{* *}$ & {$[1.297,4.438]$} \\
\hline Rural (ref: urban) & $2.569^{* * *}$ & {$[1.981,3.330]$} \\
\hline Five regions of Saudi Arabia (ref: central) & 1 & {$[1,1]$} \\
\hline Western & $1.678^{* * *}$ & {$[1.322,2.129]$} \\
\hline Eastern & $2.183^{* * *}$ & {$[1.615,2.952]$} \\
\hline Southern & $0.592^{* * *}$ & {$[0.459,0.763]$} \\
\hline Northern & 0.763 & {$[0.535,1.087]$} \\
\hline BMI WHO categories (Ref: 18.5 to 25 ) & 1 & {$[1,1]$} \\
\hline$<18.5$ & 1.397 & {$[0.717,2.720]$} \\
\hline From 25 to 30 & 1.276 & {$[0.655,2.483]$} \\
\hline More than 30 & 1.329 & {$[0.678,2.604]$} \\
\hline Cognitive impairment $^{\aleph}$ (ref: normal) & 1 & {$[1,1]$} \\
\hline Mild & $0.563^{* * *}$ & {$[0.424,0.746]$} \\
\hline Moderate & $0.471^{* *}$ & {$[0.291,0.759]$} \\
\hline Severe & $0.394^{* *}$ & {$[0.211,0.734]$} \\
\hline Depression (ref: normal) $)^{\diamond}$ & 1 & \\
\hline Suggestive of depression & $1.261^{*}$ & {$[1.013,1.570]$} \\
\hline Depression & 1.519 & {$[0.842,2.738]$} \\
\hline Diabetes mellitus & 0.882 & {$[0.742,1.049]$} \\
\hline Hypertension & 1.087 & {$[0.909,1.299]$} \\
\hline Stroke & $0.436^{*}$ & {$[0.213,0.893]$} \\
\hline Cancer & $0.395^{* *}$ & {$[0.216,0.722]$} \\
\hline Ischemic heart disease & 0.845 & {$[0.544,1.314]$} \\
\hline Metabolic disorders & $0.505^{* * *}$ & {$[0.422,0.606]$} \\
\hline Acute kidney failure and chronic kidney disease & $0.303^{* *}$ & {$[0.143,0.644]$} \\
\hline Neck pain & $1.691^{* * *}$ & {$[1.292,2.212]$} \\
\hline Back pain & $1.257^{*}$ & {$[1.051,1.503]$} \\
\hline Blood in stools & $0.543^{*}$ & {$[0.312,0.945]$} \\
\hline Headache & 1.083 & {$[0.906,1.294]$} \\
\hline Feeling fainted & $3.202^{* * *}$ & {$[2.424,4.228]$} \\
\hline Feeling fatigued & $1.725^{* * *}$ & {$[1.345,2.212]$} \\
\hline Availability of pharmacy (ref: not available) & 1 & {$[1,1]$} \\
\hline Available only & $2.188^{* *}$ & {$[1.330,3.600]$} \\
\hline Accessible only & $2.894^{* * *}$ & {$[1.638,5.111]$} \\
\hline
\end{tabular}


TABLE 2: Continued.

\begin{tabular}{lcc}
\hline Characteristics & OR & 95\% CI \\
\hline Available and accessible & 0.936 & {$[0.602,1.455]$} \\
Availability of healthcare center (ref: not available) & 1 & {$[1,1]$} \\
Available only & 0.996 & {$[0.526,1.886]$} \\
Accessible only & 0.924 & {$[0.436,1.960]$} \\
Available and accessible & 0.994 & {$[0.546,1.811]$} \\
Availability of hospital (ref: not available) & 1 & {$[1,1]$} \\
Available only & $0.556^{*}$ & {$[0.338,0.914]$} \\
Accessible only & 0.686 & {$[0.388,1.213]$} \\
Available and accessible & 1.096 & {$[0.687,1.748]$} \\
Observations & 2,946 & \\
\hline
\end{tabular}

OR : odds ratio; 95\% CI: 95\% confidence interval; BMI : body mass index; WHO:World Health Organization; ${ }^{\aleph}$ based on Short Portable Mental Status Questionnaire (SPMSQ); $\diamond$ based on Geriatric Depression Scale, ${ }^{*} P<0.05,{ }^{* *} P<0.01$, and ${ }^{* * *} P<0.001$.

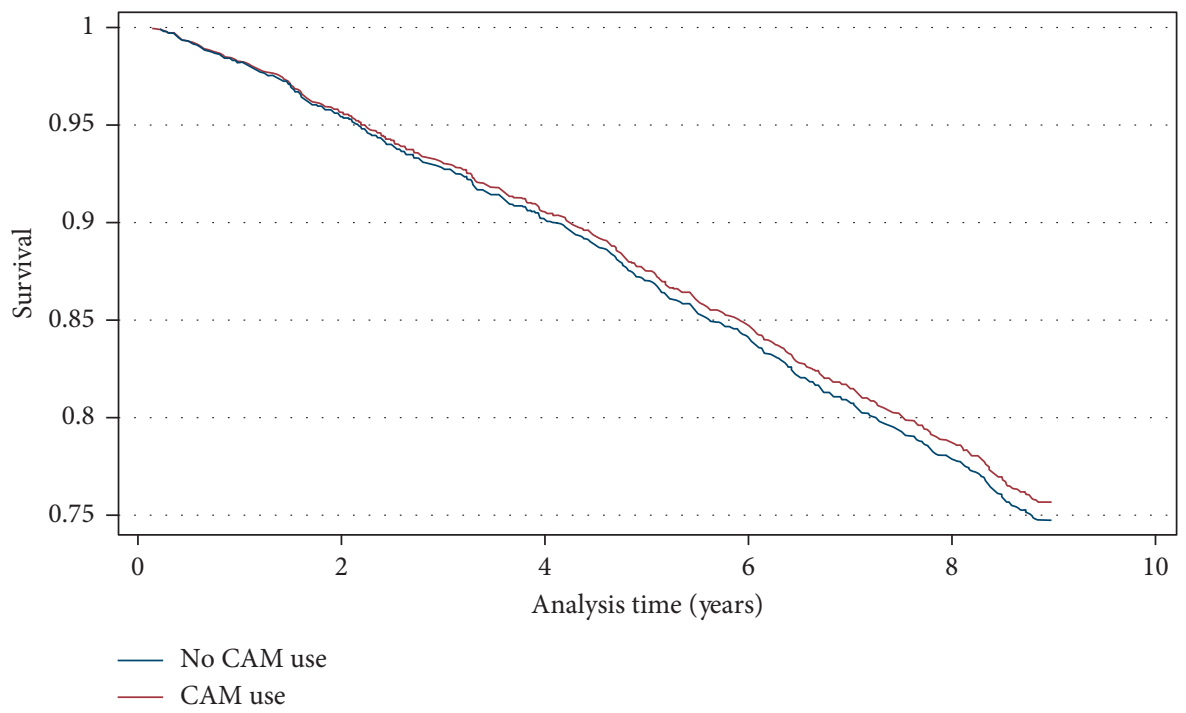

Figure 3: Survival curves based on Cox proportional hazard regression for the effect of CAM use on survival among Saudi older adults between 2006 and 2015.

considered bloodletting as a CAM. Such a technique started to become noticed again only after Olympics athletes began to use dry and wet cupping during the 2016 Olympics games despite weak scientific evidence supporting its use in sports [49].

Both the C-statistic (74.7\%) and the Hosmer-Lemeshow test $(P=0.07)$ indicated a good fit of the multivariable logistic regression. The regression model revealed that CAM utilization was not significantly different by sex. This finding is consistent with many of the published works in the literature $[1,12,16,20,50]$. However, many studies have found that CAM use was more prevalent in young females due to mass media affection, family members, and friends [5, 8, 51-53].

The facts that $46.3 \%$ of subjects stated that the reason for taking CAM is having no response to medical treatment and $31.6 \%$ were not convinced with the medical diagnosis and therapy necessitate the importance of strengthening the patient-physician relationship in order to discuss such perceptions and beliefs. Strong patient-physician relationship has shown to improve patient understanding of their disease, medications' role in improving their health, and their quality of life [54-56].
Furthermore, the aforementioned patients' beliefs about having no response to medical treatment $(46.3 \%)$ or not being convinced with the medical diagnosis or therapy (31.6\%) open the opportunity for collaborative services between physicians and pharmacists through medication therapy management clinics. These clinics can address patients' concerns regarding their current medications to improve their medication adherence over unsupported CAM use. Pharmacist-physician collaborative practices have been successful in improving outcomes among patients with chronic diseases such as those found among older adults [57-61]. Therefore, the pharmacistphysician collaboration can create a safety net for patients to express their concerns regarding their treatment plan, which in turn can reduce unnecessary use of CAM, increase adherence to treatment, and solicit a change in treatment plan when necessary.

In this study, the top four types of CAM were herbal products, acupuncture, bloodletting, and religious/Quranic rituals (Figure 1). Using a random sample of Riyadh residents, Elolemy et al. reported that herbal products (59\%), prayers $(54.6 \%)$, honey products $(54.3) \%$, and bloodletting (35.7\%) occupied the top four CAM in [5]. The difference 


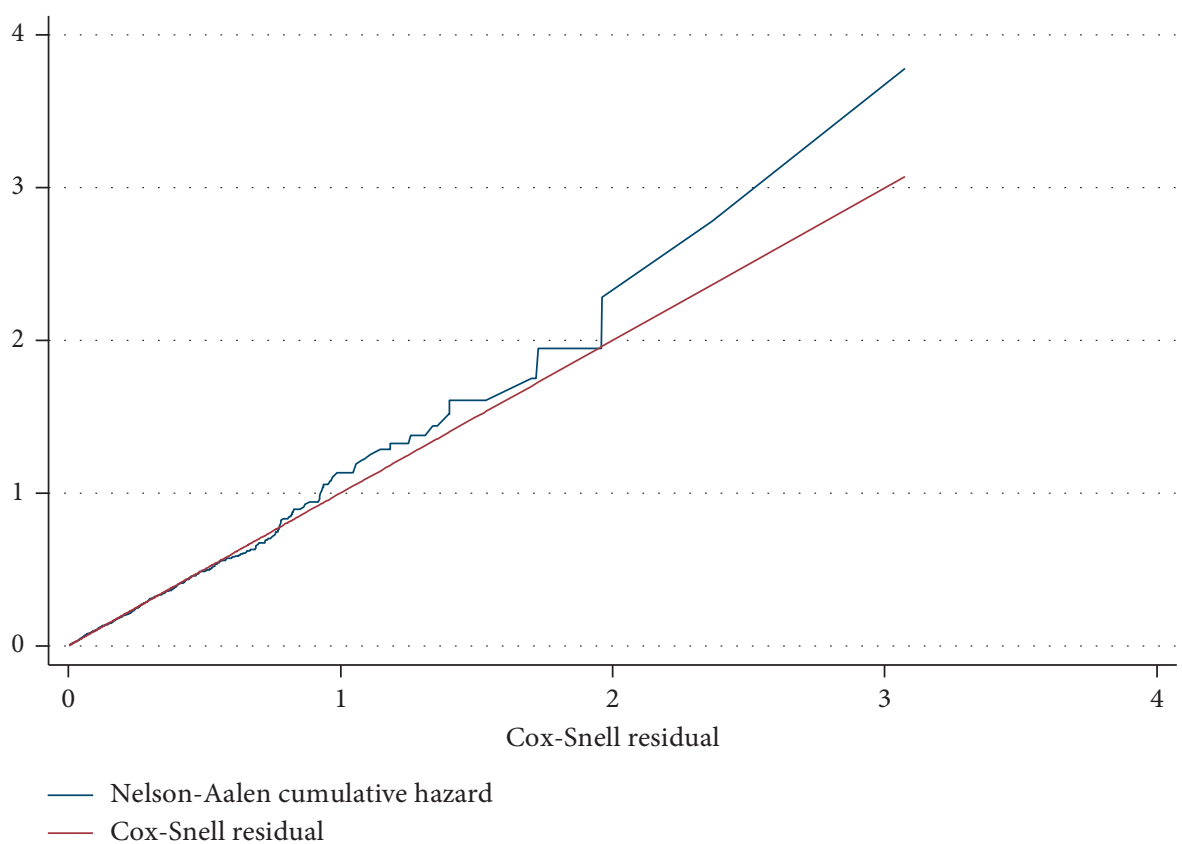

FIgUre 4: Goodness of fit test by plotting of Nelson-Aalen cumulative hazard against Cox-Snell Residuals.

between this study and the study above may be explained not only by the difference between Riyadh region and the whole kingdom but also by the subjects' case-mix as many participants were younger than this study's subjects.

Furthermore, an explanation for the high prevalence of acupuncture among SOA could be the subjects' understanding of acupuncture itself. In more detail, the literal translation of acupuncture in the Arabic language is "Chinese Injections." With 70\% illiteracy among subjects, it is most likely that the participants understood "Chinese Injections" as one form of injections that they may have been exposed to in the hospital leading to the inflated prevalence.

In the United States, during 2007, the most common types of CAM utilized by the US residents were natural products (17.7\%) and deep breathing exercises (12.7\%) [2]. The results of this study, together with the studies above, indicate the cruciality of asking patients about the use of herbal products to avoid any therapy failure due to drugherb interactions, which have been frequently documented in the literature [62-73]. Moreover, with almost $18 \%$ of subjects using CAM because of their beliefs about its usefulness (Figure 4) which may not be substantiated by scientific evidence, patients may abandon their prescribed medications and continue using CAM, leading to worsening of their disease status. For instance, Huiart and colleagues found that, among 233 patients with cancer who were receiving aromatase inhibitors (AIs), the hazard ratio of discontinuing AIs was 3.2 times greater among subjects using CAM compared to subjects who did not (95\% CI: 1.5-6.9). In their conclusion, the investigators stated that "some patients may use CAM not as a complementary treatment, but as an alternative to conventional medicine." [74]. Nevertheless, few patients share their CAM use with physicians. For instance, Sullivan et al. have reported that only $33 \%$ of patients have told their physicians about their
CAM use. The main reason for nondisclosure was "doctor never asked" [75]. Furthermore, few studies have reported that, among patients with cancer who used CAM as the sole therapy for their cancer, the risk of death was higher than patients who did not [76-78].

In this study, daily smoking was associated with a $71 \%$ increase in the odds of CAM utilization $(\mathrm{OR}=1.71 ; 95 \mathrm{CI} \%$ : 1.15-2.5). Multiple reasons may explain such behavior; for instance, Sood et al. reported that $27 \%$ of smokers have reported using CAM for smoking cessation [79, 80]. Acupuncture has been shown to reduce daily cigarette use and increased the success of quitting [81]. Moreover, since smoking increases mucus accumulation in the lungs, many smokers may end up using herbal products as expectorants or mucolytics $[82,83]$.

Regardless of CAM type, subjects who were living in rural areas were 2.57 times more likely to use CAM than the subjects in urban areas $(\mathrm{OR}=2.57 ; 95 \%$ CI: 1.98-3.33). The utilization of CAM in rural areas has been documented in different countries, including Malaysia, Australia, Nigeria, Japan, and the USA [84-88]. While almost $17 \%$ of subjects reported that the reason for CAM use is the remoteness of the hospital or health center, the regression results showed that living in rural areas was associated with increased CAM use even after controlling for healthcare accessibility to facilities such as pharmacies, healthcare centers, or hospitals. Therefore, it is most likely that among SOA, cultural beliefs and family traditions that may have been thawed in urban cities are a more prominent influencer of CAM use in rural areas than access to care. Consequently, future research should explore what beliefs and cultural habits influence the utilization of CAM among older adults in Saudi Arabia.

Concerning regional variations and the utilization of CAM (Table 2), this is the first study documenting regional 
differences in CAM use among SOA. Subjects living in the western and eastern regions were more likely to utilize CAM than subjects in the central region. It is possible that the closeness of people living in the eastern region to other Gulf countries has exposed them to CAM formulas and uses more than those in the central region. Similarly, the exposure of subjects in the western area to people coming for Hajj from almost all countries of the world may have influenced their utilization pattern. The pattern of regional variation has been reported in other countries. For instance, Nguyen and colleagues have reported that CAM utilization was higher among people living in the Central Appalachia region than the national average in the USA [89]. However, Williams et al. argued that geography itself does not explain differences in utilization, but factors such as demographic characteristics and unmet healthcare need perceived by the individuals play a more significant role [48]. Therefore, more place-specific research is needed before the hypotheses mentioned above are confirmed.

Despite the plethora of scientific research exploring CAM use among patients with cognitive impairment, there is a scarcity in such research that examines whether cognitive impairment increases or decreases CAM utilization. Almost all studies that studied cognitive impairment and CAM utilization focused on what is being used and its efficacy among patients with cognitive impairment [90-96]. We found that subjects with any level of cognitive impairment were less likely to utilize CAM than healthy subjects (Tables 1 and 2). However, it is noteworthy that almost around $50 \%$ of patients with cognitive impairments have used CAM (Table 1).

A similar trend was observed with disorders that required a strict diet. Patients with these disorders were less likely to utilize CAM (OR $=0.51$; 95\% CI: 0.42-0.61; acute or chronic kidney injuries: $\mathrm{OR}=0.30 ; 95 \% \mathrm{CI}: 0.14-0.64)$ ). In addition, patients with cancer were less likely to use CAM compared to subjects without cancer $(\mathrm{OR}=0.40 ; 95 \% \mathrm{CI}$ : $0.22-0.72$ ). However, almost $50 \%$ of subjects on metabolic disorders, $40 \%$ of subjects with kidney injuries, and $45 \%$ of patients with cancer have utilized CAM (Table 1). Patients with the abovementioned conditions could be more cautious in using CAM due to immediate effects on their health.

After adjusting for age, gender, diabetes, hypertension, stroke, obesity, cancer, ischemic heart diseases, cognitive impairment, renal failure, place of residence, smoking status, and depression, the use of CAM had neither any survival advantage nor any increase in mortality among SOA. Almost no study has demonstrated a survival benefit with CAM utilization alone while few studies have reported that a combination of CAM with conventional therapy, that is, integrated therapy, has shown survival benefits among patients with polymyositis, dermatomyositis, and advanced ovarian cancer $[38,39]$. On the other hand, few studies have reported that CAM use has led to a higher refusal of conventional therapies in cancer, leading to an increase in mortality [76-78].

Since Groennesby and Borgan test and the plot of Nelson-Aalen cumulative hazard against Cox-Snell Residuals (Figure 4) indicated a good fit of the regression model, future studies should examine the effect of CAM use on the activity of daily livings as well as the quality of life rather than survival.

The high prevalence of CAM utilization among SOA mandates the implementation of the following recommendations: first, it is essential to remind the patients and their caregivers about disclosing any CAM use to their pharmacists or physicians. Although this study showed neither beneficial nor harmful effect of CAM use on survival, such disclosure may improve patient care by avoiding the use of products with unsubstantiated evidence, decreasing unnecessary out-of-pocket cost, understanding patients' perception and believes that led to CAM use or, on the other hand, exploring potential additive or synergistic effect for the integrated therapy. Second, future studies should focus on exploring the impact of each CAM on the activities of daily living and quality of life. Third, with a high prevalence, it is vital to regulate the market of CAM in Saudi Arabia to reduce counterfeiting and ensure the authenticity of marketed products. Lastly, a collaboration between the national center of complementary medicine, the universities, and the National \& Gulf Center for Evidence-Based Health Practice should determine priorities of CAM-related research and support funding of this area of research.

Certain limitations should be taken into consideration while interpreting these results. First, due to the cross-sectional nature of the study, causality cannot be tested. Second, the lack of more details about the nature of herbal products used limits the ability to determine the most common possible herbal-drug interactions among SOA. Third, since the data was collected in 2007, the pattern of CAM utilization may have changed. Nonetheless, this study still provides valuable baseline information about CAM use among SOA. Such a baseline is essential to determine the trend of use over time.

In conclusion, this study is the first nationally representative sample that explored CAM utilization among SOA. The use of CAM was very prevalent among SOA, especially in rural areas. Despite this, the use of CAM did not demonstrate any survival benefit over nine years. Future research should focus on replicating the study to identify changes in patterns of utilization over time; exploring factors associated with the observed geographic variations will be very beneficial in directing interventions and policy decisions across the regions and determining whether or not CAM use has an impact on the quality of life rather than survival.

\section{Data Availability}

The data used to support the findings of this study are available from the corresponding author upon request.

\section{Conflicts of Interest}

The authors declare that they have no conflicts of interest.

\section{Authors' Contributions}

Both Dr. Mohammad H Aljawadi and Dr. Abdulah T Khoja contributed equally to this paper. 


\section{Acknowledgments}

The authors extend their appreciation to the Deanship of Scientific Research at King Saud University for funding this work through research group no. RG-1441-476.

\section{References}

[1] D. M. Eisenberg, R. C. Kessler, C. Foster, F. E. Norlock, D. R. Calkins, and T. L. Delbanco, "Unconventional medicine in the United States-prevalence, costs, and patterns of use," New England Journal of Medicine, vol. 328, no. 4, pp. 246-252, 1993.

[2] P. M. Barnes, B. Bloom, and R. L. Nahin, "Complementary and alternative medicine use among adults and children: United States, 2007," National Health Statistics Reports, vol. 12, pp. 1-23, 2008.

[3] Public IoMUCotUoCaAMbtA, "Complementary and alternative medicine in the united states," 2005, https://www.ncbi. nlm.nih.gov/books/NBK83796/.

[4] E. Al-Faris, N. Al-Rowais, A. Mohamed et al., "Prevalence and pattern of alternative medicine use : the results of a household survey," Annals of Saudi Medicine, vol. 28, no. 1, pp. 4-10, 2008.

[5] A. T. Elolemy and A. M. N. Albedah, "Public knowledge, attitude and practice of complementary and AlternativeMedicine in Riyadh region, Saudi Arabia," Oman Medical Journal, vol. 27, no. 1, pp. 20-26, 2012.

[6] P. M. Barnes, E. Powell-Griner, K. McFann, and R. L. Nahin, "Complementary and alternative medicine use among adults: United States, 2002," Advance Data, vol. 343, pp. 1-19, 2004.

[7] P. Fisher and A. Ward, "Medicine in europe: complementary medicine in europe,” Bmj, vol. 309, no. 6947, pp. 107-111, 1994.

[8] C. C. L. Xue, A. L. Zhang, V. Lin, C. Da Costa, and D. F. Story, "Complementary and alternative medicine use in Australia: a national population-based survey," The Journal of Alternative and Complementary Medicine, vol. 13, no. 6, pp. 643-650, 2007.

[9] D. F. Foster, R. S. Phillips, M. B. Hamel, and D. M. Eisenberg, "Alternative medicine use in older Americans," Journal of the American Geriatrics Society, vol. 48, no. 12, pp. 1560-1565, 2000.

[10] Persons AAoR, "Complementary and alternative medicine: what people 50 and older are using and discussing with their physicians," 2007, https://assets.aarp.org/rgcenter/health/ cam_2007.pdf.

[11] E. P. Cherniack, J. Ceron-Fuentes, H. Florez, L. Sandals, O. Rodriguez, and J. C. Palacios, "Influence of race and ethnicity on alternative medicine as a self-treatment preference for common medical conditions in a population of multi-ethnic urban elderly," Complementary Therapies in Clinical Practice, vol. 14, no. 2, pp. 116-123, 2008.

[12] J. A. Astin, "Why patients use alternative medicine," Jama, vol. 279, no. 19, pp. 1548-1553, 1998.

[13] R. C. Kessler, R. B. Davis, D. F. Foster et al., "Long-term trends in the use of complementary and alternative medical therapies in the United States," Annals of Internal Medicine, vol. 135, no. 4, pp. 262-268, 2001.

[14] K. Schnabel, S. Binting, C. M. Witt, and M. Teut, "Use of complementary and alternative medicine by older adults--a cross-sectional survey," BMC Geriatrics, vol. 14, p. 38, 2014.

[15] A. A. Ayele, H. G. Tegegn, K. T. Haile, S. A. Belachew, A. G. Mersha, and D. A. Erku, "Complementary and alternative medicine use among elderly patients living with chronic diseases in a teaching hospital in Ethiopia," Complementary Therapies in Medicine, vol. 35, pp. 115-119, 2017.

[16] V. Singh, D. M. Raidoo, and C. S. Harries, "The prevalence, patterns of usage and people's attitude towards complementary and alternative medicine (CAM) among the Indian community in Chatsworth, South Africa," BMC Complementary and Alternative Medicine, vol. 4, p. 3, 2004.

[17] S. H. Saydah and M. S. Eberhardt, "Use of complementary and alternative medicine among adults with chronic diseases: United States 2002," The Journal of Alternative and Complementary Medicine, vol. 12, no. 8, pp. 805-812, 2006.

[18] S. Al-Eidi, S. Tayel, F. Al-Slail et al., "Knowledge, attitude and practice of patients with type 2 diabetes mellitus towards complementary and alternative medicine," Journal of Integrative Medicine, vol. 14, no. 3, pp. 187-196, 2016.

[19] J. A. Astin, K. R. Pelletier, A. Marie, and W. L. Haskell, "Complementary and alternative medicine use among elderly persons: one-year analysis of a Blue Shield Medicare supplement," The Journals of Gerontology. Series A, Biological Sciences and Medical Sciences, vol. 55, no. 1, pp. M4-M9, 2000.

[20] K. Thomas and P. Coleman, "Use of complementary or alternative medicine in a general population in Great Britain. Results from the National Omnibus survey," Journal of Public Health, vol. 26, no. 2, pp. 152-157, 2004.

[21] Statistics GAo, "Population estimates," 2018, https://www. stats.gov.sa/en/43, Accessed 7 March, 2018.

[22] K. A. Abuelgasim, Y. Alsharhan, T. Alenzi, A. Alhazzani, Y. Z. Ali, and A. R. Jazieh, "The use of complementary and alternative medicine by patients with cancer: a cross-sectional survey in Saudi Arabia," BMC Complementary and Alternative Medicine, vol. 18, no. 1, p. 88, 2018.

[23] A. M. N. Al Bedah, M. K. M. Khalil, P. Posadzki et al., "Evaluation of wet cupping therapy: systematic review of randomized clinical trials," The Journal of Alternative and Complementary Medicine, vol. 22, no. 10, pp. 768-777, 2016.

[24] A. AlBedah, M. Khalil, A. Elolemy et al., "The use of wet cupping for persistent nonspecific low back pain: randomized controlled clinical trial," The Journal of Alternative and Complementary Medicine, vol. 21, no. 8, pp. 504-508, 2015.

[25] A. M. AlBedah, "Use of complementary and alternative medicine by cancer patients in Saudi Arabia: a paradox in healthcare," The Journal of Alternative and Complementary Medicine, vol. 19, no. 11, pp. 918-919, 2013.

[26] A. M. AlBedah and M. K. Khalil, "Cancer patients, complementary medicine and unmet needs in Saudi Arabia," Asian Pacific Journal of Cancer Prevention, vol. 16, no. 15, p. 6799, 2015.

[27] A. M. N. AlBedah, M. K. M. Khalil, A. T. Elolemy et al., "The use of and out-of-pocket spending on complementary and alternative medicine in Qassim province, Saudi Arabia," Annals of Saudi Medicine, vol. 33, no. 3, pp. 282-289, 2013.

[28] A. M. AlBedah, M. K. Khalil, and I. S. Sohaibani, "Bridging the gap between knowledge and practice in complementary and alternative medicine in Saudi Arabia," Journal of Cutaneous Medicine and Surgery, vol. 19, no. 6, p. 527, 2015.

[29] K. M. AlGhamdi, H. Khurrum, S. H. Al-Natour et al., "Use of complementary and alternative medicine among dermatology outpatients," Journal of Cutaneous Medicine and Surgery, vol. 19, no. 6, pp. 570-579, 2015.

[30] S. Al-Ghamdi, K. Aldossari, J. Al-Zahrani et al., "Prevalence, knowledge and attitudes toward herbal medication use by Saudi women in the central region during pregnancy, during 
labor and after delivery," BMC Complementary and Alternative Medicine, vol. 17, no. 1, p. 196, 2017.

[31] A. A. Al-Zahim, N. Y. Al-Malki, F. M. Al-Abdulkarim, S. A. Al-Sofayan, H. A. Abunab, and A. A. Abdo, "Use of alternative medicine by Saudi liver disease patients attending a tertiary care center: prevalence and attitudes," Saudi Journal of Gastroenterology: Official Journal of the Saudi Gastroenterology Association, vol. 19, no. 2, pp. 75-80, 2013.

[32] M. M. Jan, M. S. Basamh, O. M. Bahassan, and A. A. JamalAllail, "The use of complementary and alternative therapies in Western Saudi Arabia," Saudi Medical Journal, vol. 30, no. 5, pp. 682-686, 2009.

[33] A. R. Jazieh, R. Al Sudairy, O. Abulkhair et al., "Use of complementary and alternative medicine by patients with cancer in Saudi Arabia," The Journal of Alternative and Complementary Medicine, vol. 18, no. 11, pp. 1045-1049, 2012.

[34] F. O. Kamel, R. M. Magadmi, M. M. Hagras, B. Magadmi, and R. A. AlAhmad, "Knowledge, attitude, and beliefs toward traditional herbal medicine use among diabetics in Jeddah Saudi Arabia," Complementary Therapies in Clinical Practice, vol. 29, pp. 207-212, 2017.

[35] Y. Mohammad, A. Al-Ahmari, F. Al-Dashash et al., "Pattern of traditional medicine use by adult Saudi patients with neurological disorders," BMC Complementary and Alternative Medicine, vol. 15, p. 102, 2015.

[36] A. Mohieldin, A. Eldali, and A. Aljubran, "Knowledge, perception, and attitudes of cancer patients towards cancer and cancer care: local perspective from Saudi Arabia," Journal of Cancer Education, vol. 32, no. 2, pp. 314-319, 2017.

[37] P. Posadzki, A. M. N. AlBedah, M. M. K. Khalil, and M. S. AlQaed, "Complementary and alternative medicine for lowering blood lipid levels: a systematic review of systematic reviews," Complementary Therapies in Medicine, vol. 29, pp. 141-151, 2016.

[38] C.-M. Chang, P.-H. Shih, T.-J. Chen, W.-C. Ho, and C.-P. Yang, "Integrated therapy decreases the mortality of patients with polymyositis and dermatomyositis: a Taiwanwide population-based retrospective study," Journal of Ethnopharmacology, vol. 236, pp. 70-81, 2019.

[39] S. Linus-Lojikip, V. Subramaniam, W.-Y. Lim, and A.-S. Hss, "Survival of patients with advanced and recurrent ovarian cancer treated using integrative medicine in Malaysia: a case series," Complementary Therapies in Clinical Practice, vol. 37, pp. 73-85, 2019.

[40] E. Rakovitch, J.-P. Pignol, C. Chartier et al., "Complementary and alternative medicine use is associated with an increased perception of breast cancer risk and death," Breast Cancer Research and Treatment, vol. 90, no. 2, pp. 139-148, 2005.

[41] G. A. Roumeliotis, G. Dostaler, and K. U. Boyd, "Complementary and alternative medicines and patients with breast cancer: a case of mortality and systematic review of patterns of use in patients with breast cancer," Plastic Surgery, vol. 25, no. 4, pp. 275-283, 2017.

[42] A. T. Khoja, M. H. Aljawadi, S. A. Al-Shammari et al., "The health of Saudi older adults; results from the saudi national survey for elderly health (SNSEH) 2006-2015," Saudi Pharmaceutical Journal, 2017.

[43] W. Nelson, "Theory and applications of hazard plotting for censored failure data," Technometrics, vol. 14, no. 4, pp. 945-966, 1972.

[44] O. Aalen, "Nonparametric inference for a family of counting processes," The Annals of Statistics, vol. 6, no. 4, pp. 701-726, 1978.
[45] J. K. Grønnesby and O. Borgan, "A method for checking regression models in survival analysis based on the risk score," Lifetime Data Analysis, vol. 2, no. 4, pp. 315-328, 1996.

[46] M. T. Sturman, C. F. M. de Leon, J. L. Bienias, M. C. Morris, R. S. Wilson, and D. A. Evans, "Body mass index and cognitive decline in a biracial community population," Neurology, vol. 70, no. 5, pp. 360-367, 2008.

[47] T. C. Clarke, L. I. Black, B. J. Stussman, P. M. Barnes, and R. L. Nahin, "Trends in the use of complementary health approaches among adults: United States, 2002-2012," National Health Statistics Reports, vol. 79, pp. 1-16, 2015.

[48] A. M. Williams, P. Kitchen, and J. Eby, "Alternative health care consultations in Ontario, Canada: a geographic and socio-demographic analysis," BMC Complementary and Alternative Medicine, vol. 11, p. 47, 2011.

[49] C. Beedie, G. Whyte, A. M. Lane et al., "Caution, this treatment is a placebo. It might work, but it might not': why emerging mechanistic evidence for placebo effects does not legitimise complementary and alternative medicines in sport," British Journal of Sports Medicine, vol. 52, no. 13, pp. 817-818, 2018.

[50] J. Armishaw and C. C. Grant, "Use of complementary treatment by those hospitalised with acute illness," Archives of Disease in Childhood, vol. 81, no. 2, pp. 133-137, 1999.

[51] E. Ernst, "Prevalence of use of complementary/alternative medicine: a systematic review," Bulletin of the World Health Organization, vol. 78, no. 2, pp. 252-257, 2000.

[52] R. H. Neiberg, M. Aickin, J. G. Grzywacz et al., "Occurrence and co-occurrence of types of complementary and alternative medicine use by age, gender, ethnicity, and education among adults in the United States: the 2002 national health interview survey (NHIS)," The Journal of Alternative and Complementary Medicine, vol. 17, no. 4, pp. 363-370, 2011.

[53] H. A. Tindle, R. B. Davis, R. S. Phillips, D. M. Eisenberg, and Trends in use of complementary and alternative medicine by US adults, Alternative Therapies in Health and Medicine, vol. 11, no. 1, pp. 42-49, 2005.

[54] B. Linetzky, D. Jiang, M. M. Funnell, B. H. Curtis, and W. H. Polonsky, "Exploring the role of the patient-physician relationship on insulin adherence and clinical outcomes in type 2 diabetes: insights from the MOSAIc study," Journal of Diabetes, vol. 9, no. 6, pp. 596-605, 2017.

[55] J. E. Mariampillai, P. A. Eskås, S. Heimark et al., “Apparent treatment-resistant hypertension - patient-physician relationship and ethical issues," Blood Pressure, vol. 26, no. 3, pp. 133-138, 2017.

[56] S. Weeger and E. Farin, "The effect of the patient-physician relationship on health-related quality of life after cardiac rehabilitation," Disability and Rehabilitation, vol. 39, no. 5, pp. 468-476, 2017.

[57] M. D. Anderegg, T. H. Gums, L. Uribe, C. S. Coffey, P. A. James, and B. L. Carter, "Physician-pharmacist collaborative management: narrowing the socioeconomic blood pressure gap," Hypertension, vol. 68, no. 5, pp. 1314-1320, 2016.

[58] A. Y. Hwang, T. H. Gums, and J. G. Gums, "The benefits of physician-pharmacist collaboration," The Journal of Family Practice, vol. 66, no. 12, pp. E1-e8, 2017.

[59] P. Kulchaitanaroaj, J. M. Brooks, N. Chaiyakunapruk, A. M. Goedken, E. A. Chrischilles, and B. L. Carter, "Costutility analysis of physician-pharmacist collaborative intervention for treating hypertension compared with usual care," Journal of Hypertension, vol. 35, no. 1, pp. 178-187, 2017. 
[60] H.-W. Lin, C.-H. Lin, C.-K. Chang et al., "Economic outcomes of pharmacist-physician medication therapy management for polypharmacy elderly: a prospective, randomized, controlled trial," Journal of the Formosan Medical Association, vol. 117, no. 3, pp. 235-243, 2018.

[61] S. M. Smith, N. W. Carris, E. Dietrich et al., "Physicianpharmacist collaboration versus usual care for treatmentresistant hypertension," Journal of the American Society of Hypertension, vol. 10, no. 4, pp. 307-317, 2016.

[62] M. J. Abad, L. M. Bedoya, and P. Bermejo, "An update on drug interactions with the herbal medicine Ginkgo biloba," Current Drug Metabolism, vol. 11, no. 2, pp. 171-181, 2010.

[63] R. Al-Ramahi, N. Jaradat, R. Shalalfeh et al., "Evaluation of potential drug- herb interactions among a group of Palestinian patients with chronic diseases," BMC Complementary and Alternative Medicine, vol. 15, p. 221, 2015.

[64] C. Awortwe, M. Makiwane, H. Reuter, C. Muller, J. Louw, and B. Rosenkranz, "Critical evaluation of causality assessment of herb-drug interactions in patients," British Journal of Clinical Pharmacology, vol. 84, no. 4, pp. 679-693, 2018.

[65] A. L. Clairet, M. Boiteux-Jurain, E. Curtit et al., "Interaction between phytotherapy and oral anticancer agents: prospective study and literature review," Med Oncol, vol. 36, no. 5, p. 45, 2019.

[66] W. Cordier and V. Steenkamp, "Herbal remedies affecting coagulation: a review," Pharmaceutical Biology, vol. 50, no. 4, pp. 443-452, 2012.

[67] V. Hafner-Blumenstiel, "Phytopharmaka als Ursache von unerwünschten Arzneimittelwirkungen," Therapeutische Umschau, vol. 68, no. 1, pp. 54-57, 2011.

[68] M. S. Hussain, "Patient counseling about herbal-drug interactions," African Journal of Traditional, Complementary, and Alternative Medicines:AJTCAM, vol. 8, no. 5 Suppl, pp. 152-163, 2011.

[69] S.-W. Hwang, H.-S. Han, K. Y. Lim, and J.-Y. Han, "Drug interaction between complementary herbal medicines and gefitinib," Journal of Thoracic Oncology, vol. 3, no. 8, pp. 942-943, 2008.

[70] A. A. Izzo and E. Ernst, "Interactions between herbal medicines and prescribed drugs," Drugs, vol. 69, no. 13, pp. 1777-1798, 2009.

[71] F. Javed, A. Golagani, and H. Sharp, "Potential effects of herbal medicines and nutritional supplements on coagulation in ENT practice," The Journal of Laryngology \& Otology, vol. 122, no. 2, pp. 116-119, 2008.

[72] F. P. Turkmenoglu, Y. G. Kutsal, A. B. Dolgun, Y. Diker, and T. Baydar, "Evaluation of herbal product use and possible herb-drug interactions in Turkish elderly," Complementary Therapies in Clinical Practice, vol. 23, pp. 46-51, 2016.

[73] T. Zeller, K. Muenstedt, C. Stoll et al., "Potential interactions of complementary and alternative medicine with cancer therapy in outpatients with gynecological cancer in a comprehensive cancer center," Journal of Cancer Research and Clinical Oncology, vol. 139, no. 3, pp. 357-365, 2013.

[74] L. Huiart, A. D. Bouhnik, D. Rey et al., "Complementary or alternative medicine as possible determinant of decreased persistence to aromatase inhibitor therapy among older women with non-metastatic breast cancer," PloS One, vol. 8, no. 12, Article ID e81677, 2013.

[75] A. Sullivan, P. Gilbar, and C. Curtain, "Complementary and alternative medicine use in cancer patients in rural Australia," Integrative Cancer Therapies, vol. 14, no. 4, pp. 350-358, 2015.
[76] S. B. Johnson, H. S. Park, C. P. Gross, and J. B. Yu, "Use of alternative medicine for cancer and its impact on survival," Journal of the National Cancer Institute, vol. 110, no. 1, 2018.

[77] S. B. Johnson, H. S. Park, C. P. Gross, and J. B. Yu, "Complementary medicine, refusal of conventional cancer therapy, and survival among patients with curable cancers," JAMA Oncology, vol. 4, no. 10, pp. 1375-1381, 2018.

[78] E. Y. Chang, M. Glissmeyer, S. Tonnes, T. Hudson, and N. Johnson, "Outcomes of breast cancer in patients who use alternative therapies as primary treatment," The American Journal of Surgery, vol. 192, no. 4, pp. 471-473, 2006.

[79] A. Sood, J. Ebbert, R. Sood, and S. Stevens, "Complementary treatments for tobacco cessation: a survey," Nicotine \& Tobacco Research, vol. 8, no. 6, pp. 767-771, 2006.

[80] N. R. Waite and J. B. Clough, "A single-blind, placebocontrolled trial of a simple acupuncture treatment in the cessation of smoking," The British Journal of General Practice: The Journal of the Royal College of General Practitioners, vol. 48, no. 433, pp. 1487-1490, 1998.

[81] D. He, J. E. Berg, and A. T. Høstmark, "Effects of acupuncture on smoking cessation or reduction for motivated smokers," Preventive Medicine, vol. 26, no. 2, pp. 208-214, 1997.

[82] N. C. Liang and A. Devereaux, "Integrative medicine (complementary and alternative medicine) for the lungs," American Journal of Respiratory and Critical Care Medicine, vol. 195, no. 11, pp. P21-p22, 2017.

[83] F. L. Ramos, J. S. Krahnke, and V. Kim, "Clinical issues of mucus accumulation in COPD," International Journal of Chronic Obstructive Pulmonary Disease, vol. 9, pp. 139-150, 2014.

[84] K. M. Ariff and K. S. Beng, "Cultural health beliefs in a rural family practice: a Malaysian perspective," Australian Journal of Rural Health, vol. 14, no. 1, pp. 2-8, 2006.

[85] W. F. del Mundo, W. C. Shepherd, and T. D. Marose, "Use of alternative medicine by patients in a rural family practice clinic," Family Medicine, vol. 34, no. 3, pp. 206-212, 2002.

[86] C. E. Mbada, T. L. Adeyemi, R. A. Adedoyin et al., "Prevalence and modes of complementary and alternative medicine use among peasant farmers with musculoskeletal pain in a rural community in South-Western Nigeria," BMC Complementary and Alternative Medicine, vol. 15, p. 164, 2015.

[87] C. Meurk, A. Broom, J. Adams, and D. Sibbritt, "Rurality, mobility, identity: women's use of complementary and alternative medicine in rural Australia," Health \& Place, vol. 20, pp. 75-80, 2013.

[88] G. Shumer, S. Warber, S. Motohara et al., "Complementary and alternative medicine use by visitors to rural Japanese family medicine clinics: results from the international complementary and alternative medicine survey," BMC Complementary and Alternative Medicine, vol. 14, p. 360, 2014.

[89] D. Nguyen, P. Gavaza, L. Hollon, and R. Nicholas, "Examination of the use of complementary and alternative medicine in Central Appalachia, USA," Rural and Remote Health, vol. 14, p. 2484, 2014.

[90] K. E. Innes, T. K. Selfe, D. S. Khalsa, and S. Kandati, "A randomized controlled trial of two simple mind-body programs, Kirtan Kriya meditation and music listening, for adults with subjective cognitive decline: feasibility and acceptability," Complementary Therapies in Medicine, vol. 26, pp. 98107, 2016.

[91] K. E. Innes, T. K. Selfe, D. S. Khalsa, and S. Kandati, "Effects of meditation versus music listening on perceived stress, mood, sleep, and quality of life in adults with early memory loss: a 
pilot randomized controlled trial," Journal of Alzheimer's Disease, vol. 52, no. 4, pp. 1277-1298, 2016.

[92] K. E. Innes, T. K. Selfe, D. S. Khalsa, and S. Kandati, "Meditation and music improve memory and cognitive function in adults with subjective cognitive decline: a pilot randomized controlled trial," Journal of Alzheimer's Disease, vol. 56, no. 3, pp. 899-916, 2017.

[93] J. Landin, L. Frölich, and S. Schwarz, "Use of alternative therapies in patients with dementia and mild cognitive impairment: a prospective, controlled study," International Journal of Geriatric Psychiatry, vol. 23, no. 11, pp. 1163-1165, 2008.

[94] J. M. Moran and J. D. Pedrera-Zamorano, "Comments on Efficacy and safety assessment of acupuncture and nimodipine to treat mild cognitive impairment after cerebral infarction: a randomized controlled trial," BMC Complementary and Alternative Medicine, vol. 17, no. 1, p. 119, 2017.

[95] S. Wang, H. Yang, J. Zhang et al., "Efficacy and safety assessment of acupuncture and nimodipine to treat mild cognitive impairment after cerebral infarction: a randomized controlled trial," BMC Complementary and Alternative Medicine, vol. 16, p. 361, 2016.

[96] L. Zeng, Y. Zou, L. Kong et al., "Can Chinese herbal medicine adjunctive therapy improve outcomes of senile vascular dementia? Systematic review with meta-analysis of clinical trials," Phytotherapy Research, vol. 29, no. 12, pp. 1843-1857, 2015. 